\title{
Reproduction of the male eastern pipistrelle, Pipistrellus subflavus, in the north-eastern United States
}

\author{
P. H. Krutzsch and E. G. Crichton* \\ Department of Anatomy, University of Arizona, Tucson, Arizona 85724, and Department of \\ Anatomy and Histology, University of Adelaide, Adelaide, South Australia 5001, Australia
}

\begin{abstract}
Summary. The major reproductive events in the male eastern pipistrelle, are similar to those of other hibernating vespertilionids. The eastern pipistrelle stores epididymal spermatozoa throughout hibernation, a time when the testes are involuted but accessory gland activity is maintained. However, this species differs from others in that epididymal and testicular spermatozoa persist longer and the weights of the accessory glands are not strongly differentiated between winter and spring/summer. It is suggested that the reproductive period is extended in this species as a function of a more prolonged period of hibernation, resulting in only a brief period of sexual quiescence in mid-summer. The eastern pipistrelle (Pipistrellus subflavus) resembles the canyon bat $(P$. hesperus) in that some testicular spermatozoa persist during winter. Many aspects of the reproductive anatomy and chronology of these two species are similar; however, eastern pipistrelles apparently lack a seminal vesicle and possess a distinctly different baculum.
\end{abstract}

\section{Introduction}

Most vespertilionid bats found in the temperate zones of North America (north of the Mexican border) undergo extended hibernation or periodic deep torpor during winter. The resultant prolonged or widely intermittent reduction in metabolism during these periods may delay, block or alter numerous physiological functions, anatomical cycles or growth patterns, biochemical synthetic or elaborative activities and/or target organ responses. It is therefore not surprising that the basic reproductive pattern displayed by heterothermic (hibernating) bats which reside in this geographic region is particularly unique.

The reproductive cycles of a number of representative species of hibernating vespertilionids have been recorded (Guthrie, 1933; Miller, 1939; Wimsatt, 1944, 1945, 1960, 1969; Pearson, Koford \& Pearson, 1952; Krutzsch, 1961, 1964, 1975; Racey, 1974; Racey \& Tam, 1974). Characteristically, by the time of onset of hibernation spermatogenesis is completed, the testes have regressed and mating has occurred. However, epididymidal spermatozoa and accessory sex gland secretory stores are maintained throughout the winter. During this period of lowered metabolism, testicular atrophy but continued libido, Leydig cells of little brown bats (Myotis lucifugus lucifugus) are regressed (Gustafson, 1976) and androgen concentrations are low (Gustafson \& Shemesh, 1976; Gustafson, 1979); these authors suggest that the very high levels of androgens measured during late spermatogenesis may prime the accessory organs and thus maintain them throughout hibernation. Other species in which continued hypertrophy of the Leydig cells seems to be maintained during hibernation, also demonstrate extremely high concentrations of androgens (Racey, 1974; Racey \&

\footnotetext{
*Present address: Department of Anatomy and Histology, University of Adelaide, Adelaide, South Australia 5001,
} Australia. 
Tam, 1974). These various specializations contribute to the potential for fertile copulations throughout hibernation and provide for the possibility of a brief interval of insemination after arousal in the spring (when ovulation occurs), an adaptation that presumably ensures another opportunity of insemination to those females that may have lost their stored spermatozoa. Since sperm storage in the female reproductive tract and delayed ovulation are also associated with, and likely related to, the reduced metabolism during hibernation (Pearson et al., 1952; Wimsatt \& Trapido, 1952), these female and male patterns are clearly biologically complementary events.

Reduced temperatures accompanying autumn may not be the only factor regulating these reproductive events. Beasley \& Zucker (1984) studied the pallid bat (Antrozous pallidus) and showed that photoperiod may play a role, especially in promoting testicular regression and sperm storage; furthermore, it has been suggested that the response is mediated by the pineal gland (Beasley, Smale \& Smith, 1984).

The present study describes some aspects of the reproductive cycle of another North American vespertilionid, the eastern pipistrelle (Pipistrellus subflavus). This species has a wide range throughout the eastern United States, from Nova Scotia, Quebec and Minnesota southward to the Gulf, to Guatemala and Honduras (Barbour \& Davis, 1969). Little is known of its reproduction, except that copulation has been observed in November and sperm storage until late April (Guthrie, 1933; Jennings, 1958). Births have been recorded in May/June (Florida) and June/July (West Virginia and Kentucky) and there are usually 2 young (Barbour \& Davis, 1969).

\section{Materials and Methods}

Bats were obtained alive from their natural roosting places at various localities in New York, Pennsylvania and West Virginia at intervals during the period from October, 1958 to August, 1964.

Animals were brought directly to the laboratory where they were categorized as to sexual maturity (Table 1) and then killed by an overdose of ether or cervical dislocation. The reproductive organs were immediately removed and freed of extraneous fat and connective tissue. Individual organs were weighed on a torsion balance to the nearest $0.1 \mathrm{mg}$. Representative samples of the dissected organs to be utilized for histological examination were then fixed in aqueous Bouin's fluid, $10 \%$ neutral formalin or cold Rossman's fluid, dehydrated in graded alcohols, embedded in

Table 1. Summary of characteristics which together allow juveniles to be distinguished from adult male eastern pipistrelles during the late summer-fall of the first year

\begin{tabular}{|c|c|c|}
\hline Characteristic & Juvenile & Adult \\
\hline Pelage & $\begin{array}{l}\text { Short, woolly, dark (through } \\
\text { summer-winter first year) }\end{array}$ & Long, smooth \\
\hline Phalangeal joints & $\begin{array}{l}\text { Elongated spindle-shaped; wide, thick } \\
\text { epiphyseal cartilage (through summer } \\
\text { of first year) }\end{array}$ & $\begin{array}{l}\text { Truncate-flat, knobby, short joint; } \\
\text { epiphyseal cartilage, very thin, flat }\end{array}$ \\
\hline \multicolumn{3}{|c|}{$\begin{array}{l}\text { Reproductive tract (late } \\
\text { summer and autumn) }\end{array}$} \\
\hline Testes & $\begin{array}{l}\text { Seminiferous tubules, small diameter, } \\
\text { lumina small with Sertoli cells and } \\
\text { spermatogonia only; cauda } \\
\text { epididymidis small diameter, no } \\
\text { spermatozoa }\end{array}$ & $\begin{array}{l}\text { Seminiferous tubules, larger diameters, } \\
\text { lumina large with many spermatozoa, } \\
\text { cauda epididymidis, large with many } \\
\text { spermatozoa }\end{array}$ \\
\hline Accessory glands & $\begin{array}{l}\text { Small, tiny sinusoids, little or no } \\
\text { secretory material in lumina }\end{array}$ & $\begin{array}{l}\text { Large, large sinusoids with much } \\
\text { secretory material }\end{array}$ \\
\hline Teeth & Needle-sharp, unworn & $\begin{array}{l}\text { Not needle-sharp, varied degrees of } \\
\text { wear }\end{array}$ \\
\hline
\end{tabular}


paraffin wax, sectioned at $5 \mu \mathrm{m}$, mounted on glass slides and stained according to the following techniques: Harris' haematoxylin and eosin (for general microstructure), Masson's trichrome stain (for connective tissue and general microstructure) and Wilder's silver impregnation (for reticulum fibres) (Humason, 1967).

During a period of 13 months (June 1961-June 1962) bats were obtained twice a month and brought to the laboratory where their freshly dissected reproductive organs were immediately processed in the cold to measure ascorbic acid or fructose. Both testes of each pair were separately assayed for ascorbic acid by the method of Roe \& Kuether (1943). This method is sensitive to amounts of ascorbic acid down to $0 \cdot 2 \mu \mathrm{g} / \mathrm{ml}$ filtrate. A standard curve was prepared for each assay. The prostate and paired ampullary and Cowper's glands were likewise separately assayed for fructose according to the method of Lindner \& Mann (1960). Results were calculated from a calibration curve which was prepared for each assay with standard dilutions of pure fructose. The assay sensitivity was $2 \mu \mathrm{g} / \mathrm{ml}$ sample.

Using an optical micrometer, measurements were made of two diameters at right angles of 12 Leydig cells for 2-5 animals each month, and counts were made from 2 specimens/month of the numbers of seminiferous tubules containing spermatozoa in 5 random fields.

\section{Observations}

The gross organization of the reproductive tract of the male eastern pipistrelle (Fig. 1) differs from that of its putative nearest North American relative (the canyon bat, Pipistrellus hesperus) by the absence of seminal vesicles, the presence of paired ampullary glands, and in the morphology of the os penis (baculum).

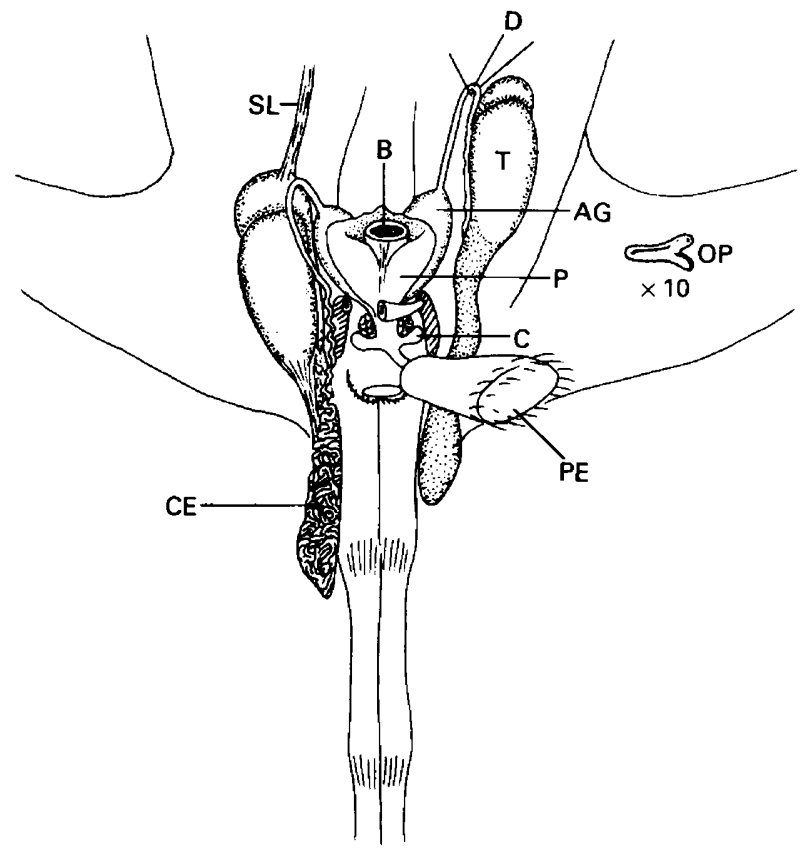

Fig. 1 The reproductive system of the male eastern pipistrelle, ventral view. Line drawing from a freshly dissected specimen showing the ampullary gland (AG), bladder (B), Cowper's gland $(C)$, cauda epididymidis (CE), prostate gland $(\mathrm{P})$, penis (PE), suspensory ligament of testis (SL), testis (T), ductus deferens (D) and os penis (OP). $\times \sim 4$. On the right side, the outer membrane of the cauda epididymidis has been stripped to reveal the tubules. On the left side a loop has been placed around the ductus deferens, thus better displaying the testis and epididymis by drawing them up from their normal position in situ. 


\section{Gross anatomy of reproductive organs}

Testis and epididymis. The testes of the adult are elongated, ovoid or elliptical structures with the caput and corpus epididymidis closely applied on the dorsomedial aspect. The testes, which are always external to the body cavity, lie on the medial ventral surface of the thigh enclosed in a sacculation of the obliquus externus abdominis fascia ( = external spermatic fascia). The cauda epididymidis on each side may extend this fascial pouch for various distances into the interfemoral membrane where they lie alongside the caudal vertebrae. The pouch is distally pigmented (black) and elongates in the late summer-early autumn to accommodate the coiled epididymal tails as they become filled with spermatozoa. The cauda epididymidis remains as a conspicuous elongated coiled body until the spermatozoa are cleared after spring arousal. The epididymides then retract to the testis and become externally inconspicuous. The pouch remains as a dark thread-like line alongside the caudal vertebrae in the interfemoral membrane.

The cauda epididymidis passes medially and cephalad across the posterior surface of the testis and straightens terminally to become the ductus deferens. The ductus enters the abdominal cavity through the inguinal canal as one of the components of the spermatic cord. Within the abdominal cavity the ductus deferens leaves the other components of the spermatic cord (internal spermatic nerve, spermatic artery and spermatic vein), passes medially and loops dorsal to the ureter; it dilates terminally as it joins the ampullary gland.

Accessory sex glands. The accessory glands consist of paired Cowper's and ampullary glands and a single bilobed (ventrally incomplete) prostate gland.

The prostate gland is funnel-shaped, concave on its cephalic surface and convex caudally. The funnel encloses the urethra distally but is incomplete on its ventral surface in front of the neck of the bladder. Its free surfaces are enclosed by a dense connective tissue and smooth muscle capsule. The dorsal surface of the prostate is in close juxtaposition with the paired, conical-shaped ampullary glands and the dense connective tissue and smooth muscle capsules of the two glands are in side-by-side contact with little intervening space. Laterally, the curving margins of these organs result in a wedge-shaped space at each side that contains loose connective tissue, fat and reticular fibres enclosing the blood vessels and nerves travelling to and from the glands.

The urinary bladder rests in a depression on the cephalic surface of the prostate and lies ventral to the ampullary glands. The urethra passes through the substance of the prostate gland, where it accepts multiple ducts from the surrounding prostate as well as the deferent ducts from the terminal central canal of the ampullary glands.

The penile urethra emerges from the prostate distally as a tube, expands slightly to become the bulbous segment and receives bilaterally the duct from each of the paired Cowper's (bulbourethral) glands. The Cowper's glands are small, oblong in shape and lie slightly ventral and lateral to the anus where they are visible in the perineal fat. The glands are encapsulated in a dense connective tissue and smooth muscle tunic which is covered at the bulbous end by a thick layer of skeletal muscle that tapers to disappear at the narrow end of the gland where the main duct emerges.

Fig. 2. Testes of adult bats obtained at different times of year. $H \& E, \times 460$. (a) Male obtained in early June showing small size of seminiferous tubules (ST) and absence of spermatogenic activity. (b) Male obtained in late July showing the increased size of seminiferous tubules (ST), intense spermatogenic activity, with all stages of gamete formation, and occasional spermatozoa (SZ). (c) Male obtained in early September showing further increased size of seminiferous tubules (ST), the presence of spermatozoa (SZ) and reduced production of early stages in spermatogenesis. (d) Male obtained in November. Note the presence of many spermatozoa (SZ) in Sertoli cell cytoplasm. (e) Male obtained in December. Spermatozoa (SZ) are still abundant. Note the presence of cellular debris (arrowed) within the seminiferous tubule (ST) lumen. (f) Male obtained in April. Note the reduction in diameter of the seminiferous tubule (ST) and in the height of the epithelium. Some spermatozoa (SZ) are still present. 

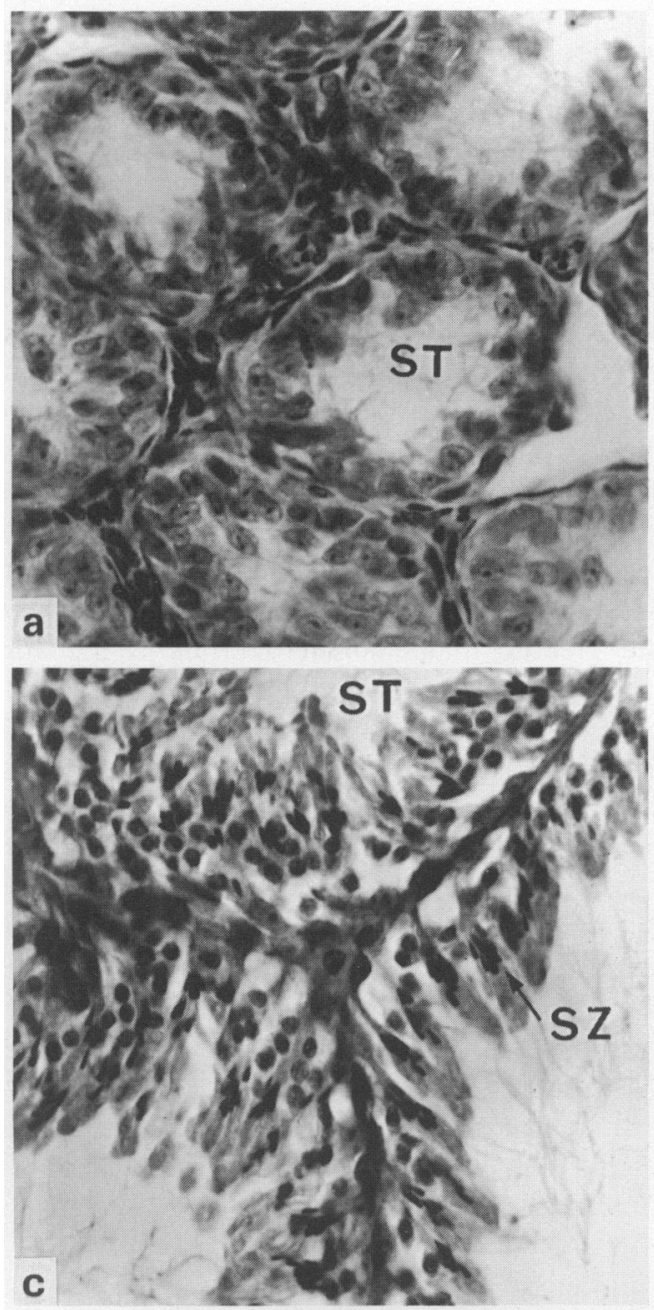

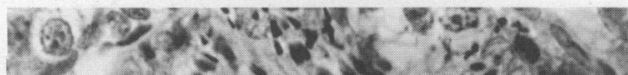

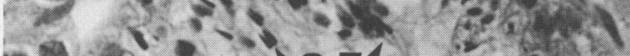

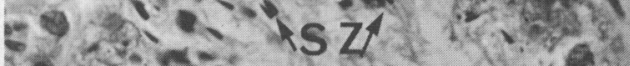

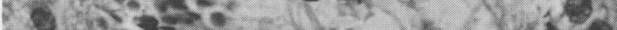

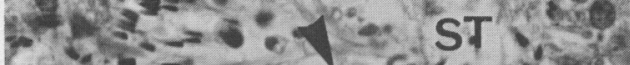

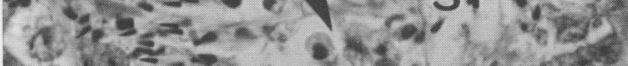

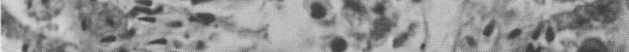

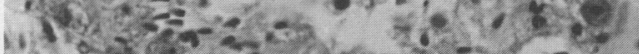

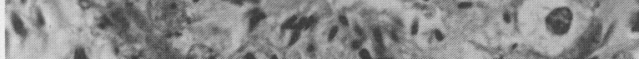

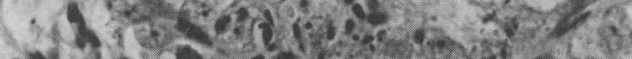

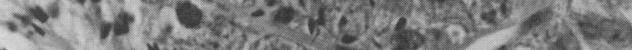

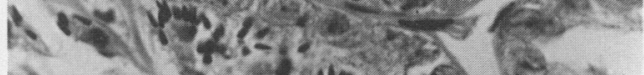

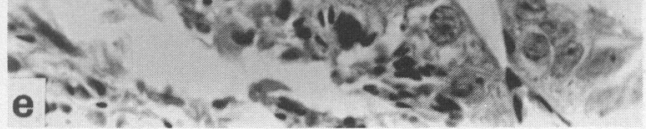

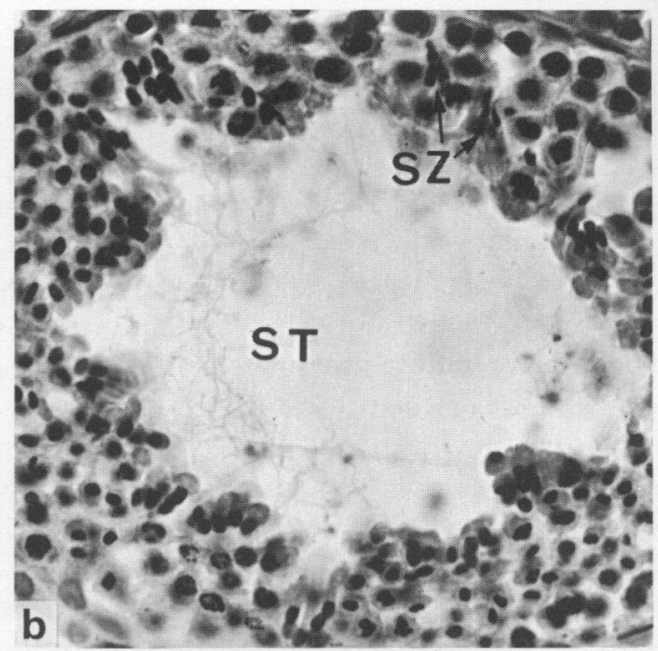

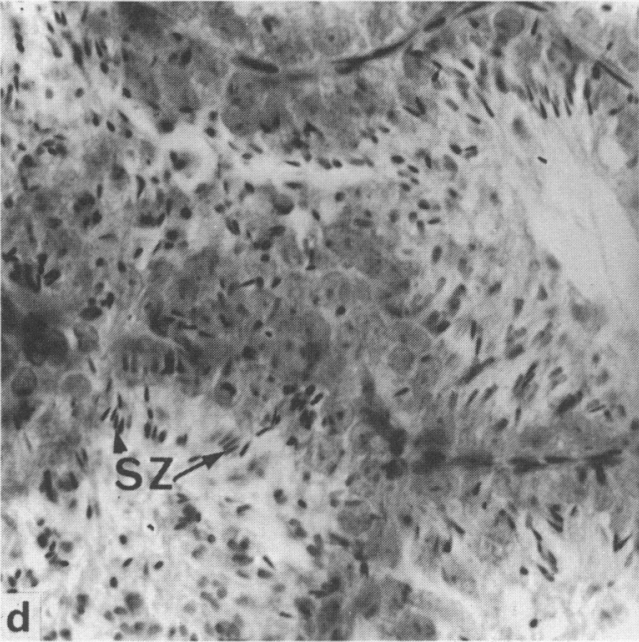

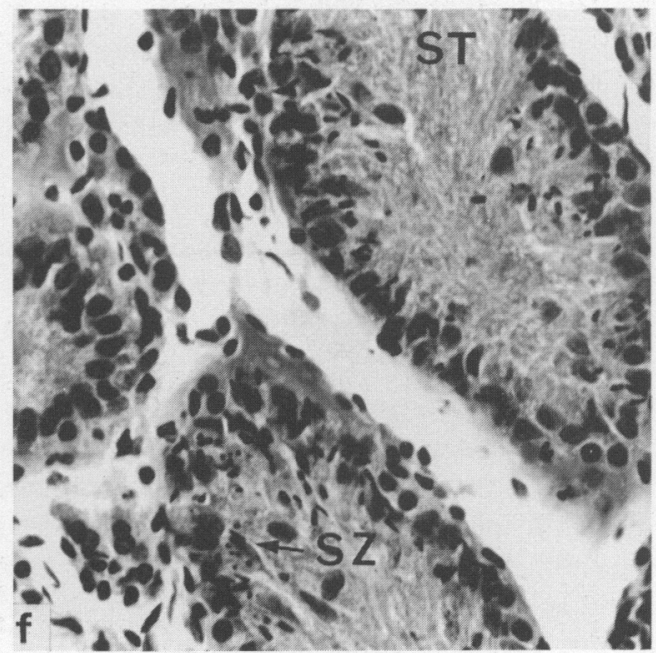




\section{Microstructure and annual reproductive cycle}

Testes. Although a few spermatozoa were occasionally found in the seminiferous tubules of young bats of the year (in their first autumn) sexual maturity was not normally achieved before the autumn of the beginning of the 2 nd year.

The testes of adult bats were involuted in June (Fig. 2a) but began to enlarge in July, and achieved maximum dimensions in August (Fig. 4). A decline in weight and size began in September and continued until November when the testes became involuted. The testes remained involuted throughout the hibernation period and following arousal until the early summer.

These annual changes in weight and dimension expressed the functional testicular cycle as confirmed histologically (Fig. 1) and biochemically (Fig. 4). Beginning in July the weight increase in the testes was accompanied by a marked histological change. There was a wave of spermatogenic activity (Fig. 5), as indicated by increasing numbers of primary spermatocytes, and this was accompanied by the increasing diameter of the seminiferous tubules. By mid-July the germinal epithelium of most seminiferous tubules was filled with dividing cells of advanced spermatogenic stages. By late July (Fig. 2b), the seminiferous tubules had further enlarged, spermatogenesis was underway in virtually all tubules and had proceeded to the spermatid stage in many. In August and early September seminiferous tubules achieved their greatest diameter and spermiogenesis was dominant with few primary and secondary spermatocytes evident (Fig. 2c). Tubules were packed with spermatids at their luminal border and most were clearly associated with Sertoli cell cytoplasm. Acidophilic cytoplasmic droplets (residual bodies) were visible in the tubules; they were most abundant in September when spermatozoa were present. In October-November (Fig. 2d) spermatogenesis was completed and there was a general reduction in tubular size and cellular activity although many spermatozoa could still be seen in some of the larger tubules. The testes continued to decrease in weight. However, a large number of seminiferous tubules in a crosssectional testicular preparation contained a prominent population of spermatozoa at the onset of hibernation (November to January; Figs 2e \& $2 \mathrm{f}$ ). Some spermatozoa persisted in isolated tubules throughout the rest of hibernation and occasional spermatozoa were present as late as early June in the seminiferous tubules of some males collected while in torpor from cave environments.

Data from chemical analyses for ascorbic acid of homogenates of the testes throughout the year closely paralleled the annual changes in testicular weight (Fig. 4); i.e. ascorbic acid content was low during testicular involution $\left(0 \cdot 5-2 \cdot 0 \mu \mathrm{g} /\right.$ testes) and higher during testicular hypertrophy $\left(9 \cdot 0^{-}\right.$ $11.5 \mu \mathrm{g} /$ testes). The pattern for each parameter (i.e. histological sequence, testicular weight, ascorbic acid level) varied in onset and duration but all were relatively synchronized.

The interstitial cells of Leydig (Fig. 5) began to enlarge in February (mean area = $52 \cdot 2 \pm 3 \cdot 1 \mu \mathrm{m}^{2}, \quad n=5$ ), and reached their maximum size in August (mean area $=$ $118.8 \pm 7 \cdot 3 \mu \mathrm{m}^{2}, n=2$ ) at which time their cytoplasm was eosinophilic and often appeared granular and/or vacuolated. In September the interstitial cells, though still enlarged (mean area $=88.0 \pm 9.6 \mu \mathrm{m}^{2}, n=5$ ) had begun to regress and they continued to decrease over the ensuing months. Leydig cell area was smallest from December to April, when the nucleus was often pycnotic and the scant cytoplasm did not display vacuoles, granules or eosinophilia.

Epididymis. The diameter of the lumen of the epididymal tubules varied with the sperm content, being largest when crowded with spermatozoa and smaller at other periods. Spermatozoa were first seen in the epididymis in late August-early September and by mid-September virtually all caput epididymal sections were packed. Spermatozoa quickly moved to the caudal segments and as the caput population decreased caudal tubules were packed and diameters increased. Mating probably began in late August/early September and continued until November. Caudal tubules remained filled with spermatozoa until the end of hibernation (March/April) and bats obtained from spring and summer (June/July) cave populations, which were torpid at capture, frequently had abundant cauda epididymal spermatozoa. In these and active bats, spermatozoa were present as late as July both in the cauda epididymidis and in the ductus deferens, primarily at its distal dilatation, at its 
junction with the ampullary gland. Examination of the testes of these animals revealed that the new cycle of the seminiferous epithelium had not reached the spermiogenic stage.

Accessory sex glands. As was true of the testes, the accessory sex glands of juveniles demonstrated only slight microscopic changes, little luminal secretion and no consistent size variation in their first year and apparently are essentially non-secretory stromal organs.

As compared with the testes, the prostate (Fig. 6a), ampullary (Fig. 6b) and Cowper's glands of adults showed less seasonal variation as judged by their weight, size, and microscopic and quantitative observations on their secretory content. However, it is recognized that these parameters could be markedly influenced by copulatory activity and are not therefore necessarily a true indicator of the secretory characteristics of the epithelia of these organs. The data suggest that their functional cycle began in October (i.e. shortly after the testicular cycle waned) when peak weight and fructose content occurred. It is likely that most of the population mates during this month. The high levels of secretion and glandular hypertrophy around the time of mating were not continuously maintained throughout the period of hibernation when considerable fluctuation in size and fructose content of the accessory glands was recorded. This may be a reflection of intermittent copulatory activity, but the glands apparently contained fructose for most of the year.

The prostate is made up of numerous branched tubuloalveolar glands with a secretory epithelium that showed only small differences in height seasonally.

The prostate glands began to increase in weight and in secretory content in August, soon after the start of testicular redevelopment, and continued until late October. Accompanying the increase in size and fructose content of the prostate the alveoli became distended with secretion and the luminal epithelium was flattened. Although fluctuations in prostate gland size and fructose content occurred, there was relatively little significant change in these measures throughout the winter and early spring (Figs 3a \& 3b). Enlarged, active alveoli were filled with granular, acidophilic secretion products which varied in size and shape. The smooth muscle and fibrous connective tissue stroma between alveoli was less conspicuous or reduced in active glands, whereas in involuted and juvenile presecretory glands a prominent fibrous connective tissue and smooth muscle interalveolar stroma was typical.

Fructose was present at all seasons (Fig. 6a) but occurred at highest levels during the period of greatest prostate hypertrophy (late October: $19 \cdot 0 \mu \mathrm{g} /$ prostate) which follows the onset of testicular involution (Fig. 4). The fructose content of the prostate was lowest in the summer (July: $1 \cdot 0-3.0 \mu \mathrm{g} /$ prostate).

There were no spermatozoa in the prostatic ducts or alveolar system.

The ampullary glands receive the terminal dilated portion of the ductus deferens on their dorsolateral, cephalic surface and the canals of these two organs are continuous. The mucosa of the central canal was highly folded and outpouched with resultant alveolar-like spaces that appeared to be more or less concentrically arranged around the central canal. These glandular spaces were lined by secretory epithelium which was compressed and almost squamous in appearance (Fig. 3a) when the lumina were filled with granular secretions, whereas in empty or nearly empty alveoli the cells had a columnar or high cuboidal epithelium (Fig. 3b).

In active glands the secretion appeared to be retained in greatest quantity in the more peripheral alveoli and there the epithelium was lowest. Alveoli immediately adjacent to the central canal were smallest in diameter, often empty of secretion and lined by a secretory epithelium of cuboidal or columnar cells.

Spermatozoa were frequently present in the central canal throughout hibernation and early spring but were progressively fewer in number in each more adjacent circle of alveoli and were virtually never seen in terminal sacculations. Spermatozoa were rarely seen in the luminal secretions in ampullary glands obtained from adult bats in late spring and early summer.

Chemical analyses for fructose of homogenates of the ampullary glands of adult eastern pipistrelles revealed that this sugar was present at all seasons (Fig. 6b). After reaching their lowest 

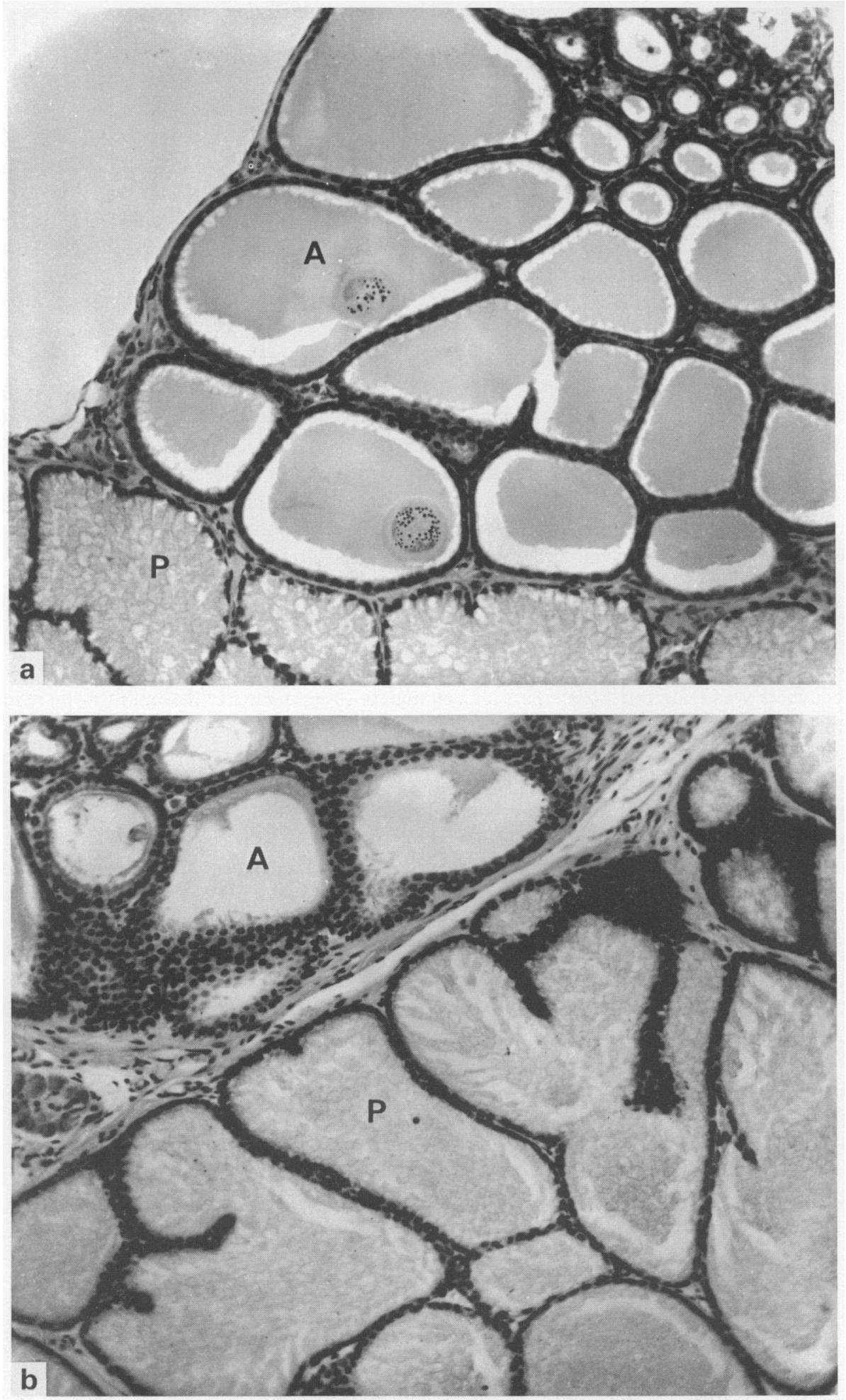

Fig. 3. Prostate (P) and ampullary gland (A) from adult bats obtained in (a) late December and (b) before arousal in April. In (b) there is reduced secretion product in the ampullary gland and higher luminal epithelial profiles than in (a). H \& E, $\times 290$. 


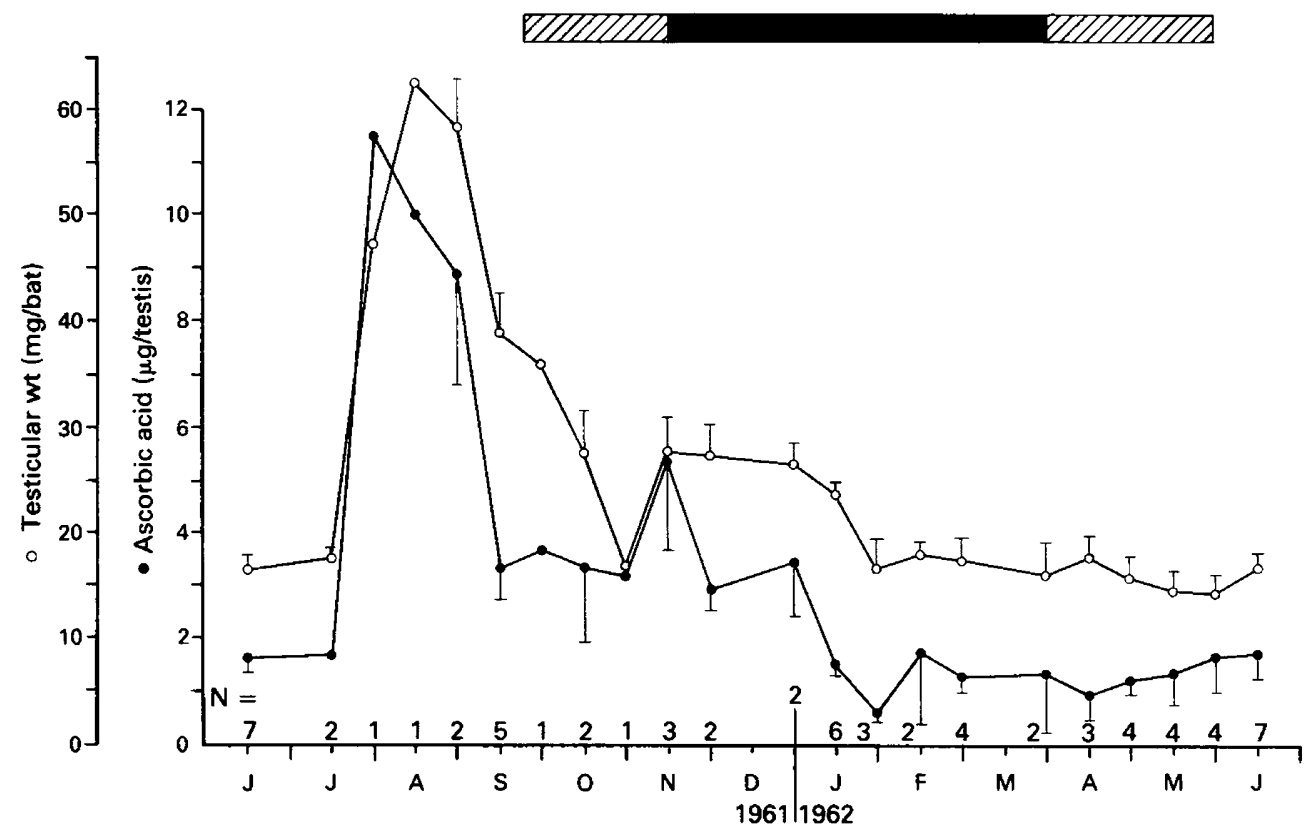

Fig. 4. Weight of the paired testes and ascorbic acid content throughout the annual reproductive cycle in eastern pipistrelles. Values are mean \pm s.e.m. for the numbers of animals indicated. The times of intermittent (hatched bar) and deep (solid bar) hibernation are indicated.

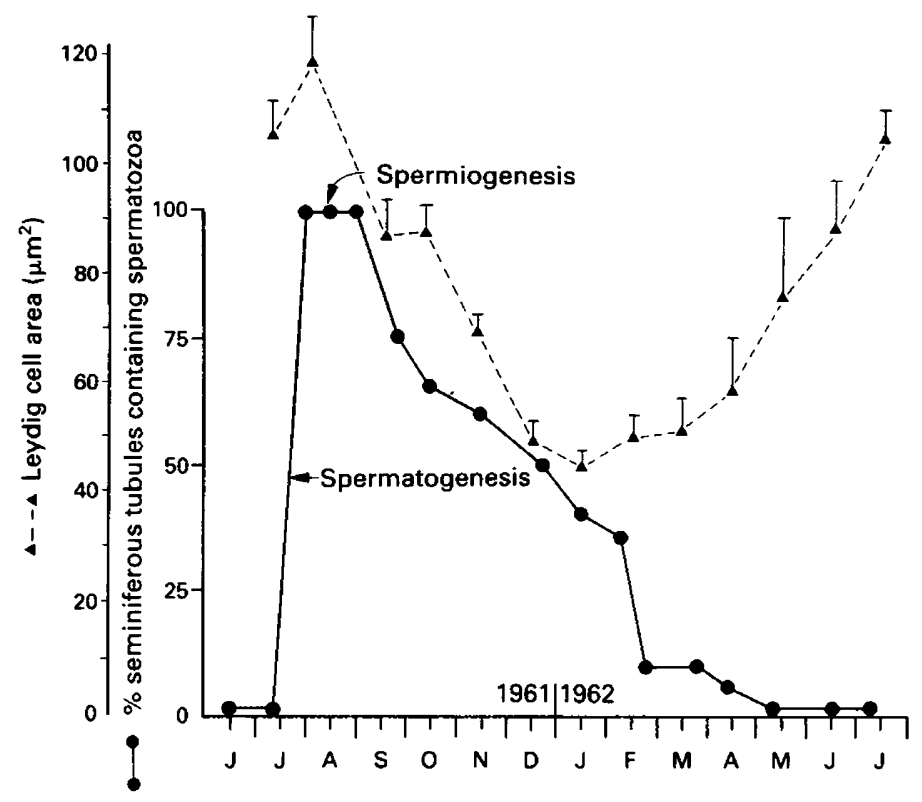

Fig. 5. The area of Leydig cells and the percentage of seminiferous tubules containing spermatozoa at monthly intervals over parts of two consecutive years in eastern pipistrelles. The times when spermatogenesis and spermiogenesis are apparent are indicated. Values are mean \pm s.e.m. for $2-5$ bats/month. 

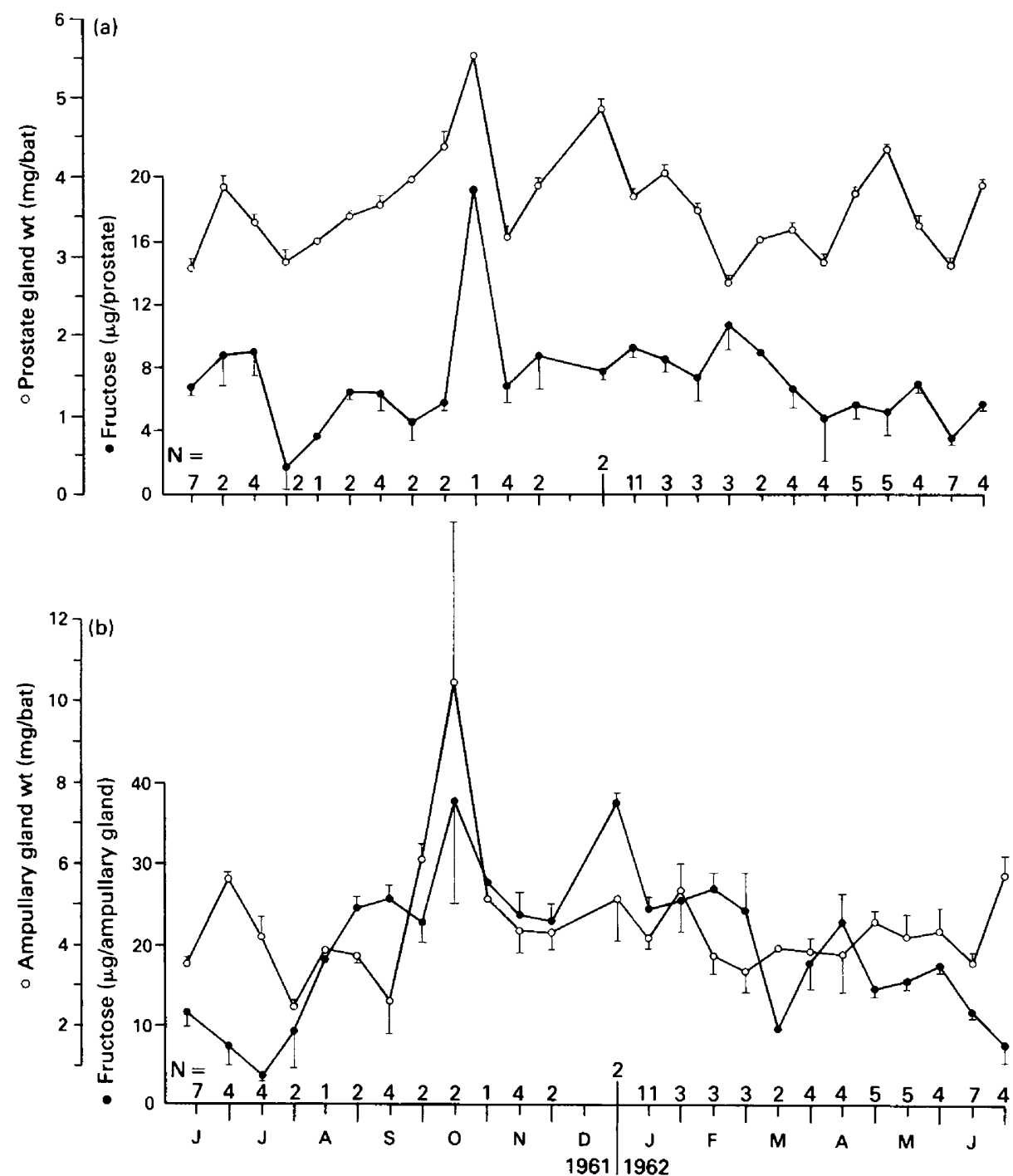

Fig. 6. Weight and fructose content of (a) the prostate gland and (b) the ampullary gland in eastern pipistrelles over parts of two consecutive years. Values are mean \pm s.e.m. for the number of bats indicated for each sample.

level in mid-July ( $4.0 \mu \mathrm{g}$ fructose/gland), fructose levels rose in concert with increasing ampullary gland weight between late July (10.0 $\mu \mathrm{g}$ fructose/gland) and mid-October ( $38.0 \mu \mathrm{g}$ fructose/gland). This interval overlapped testicular involution and corresponded to the late summer and autumn period of preparation for breeding before hibernation (October). High fructose values were also recorded in December (38.0 $\mu \mathrm{g}$ fructose/gland).

Cowper's glands showed little seasonal change in their secretory state and gross size. The ducts and central canal draining these tubuloalveolar organs usually contained a fine granular or homogeneous eosinophilic luminal substrate somewhere along their course. At any one time of the year some terminal alveoli were actively secreting whereas others were not. Chemical analyses for fructose of homogenates prepared from Cowper's glands were negative. 


\section{Baculum}

This bony ossicle was Y-shaped, with the prongs of the $\mathrm{Y}$ directed proximally (Fig. 1). There was a shallow concave depression along its entire ventral surface which conformed to the convex curve of the dorsal surface of the tubular urethra to which it was closely applied in the glans penis. The os penis was small (mean length $=0.76 \pm 0.02 \mathrm{~mm}, n=12$ ) and the distal shaft ended in a bluntly rounded tip.

\section{Discussion}

In the anatomical arrangement of its reproductive organs the eastern pipistrelle differs in several ways from the canyon bat (Krutzsch, 1975). Firstly, the ampulla of Henle in the canyon bat appears to be incorporated into a surrounding seminal vesicle whereas in the eastern pipistrelle the ductus deferens seems to enlarge and merge into a higly folded glandular structure (the ampullary gland?), which apparently lacks a surrounding gland homologous to the seminal vesicle of the canyon bat, although the microstructure of these two glands is strikingly similar. Secondly, the baculum of the eastern pipistrelle is much smaller and is distinctly different in its morphology than that of the canyon bat (Hamilton, 1949; Krutzsch, 1975).

The chronology of the major reproductive events in the annual cycle of the male eastern pipistrelle corresponds in most ways to the annual cycle described for a number of temperate zone hibernating vespertilionid bats of North America (Miller, 1939; Pearson et al., 1952; Christian, 1956; Krutzsch, 1961, 1964, 1975; Gustafson, 1976, 1979). However, there are several distinctions. Testicular involution is not accompanied by the complete disappearance of testicular spermatozoa. Small numbers of spermatozoa persist in the seminiferous tubules during hibernation and occasional gametes are seen as late as spring (May-June), which may be several weeks after arousal from hibernation. A similar situation has been noted in the canyon bat (Krutzsch, 1975). It is possible that, in both species, these persisting testicular spermatozoa are merely residual gametes, never destined for normal ejaculation. Racey (1979), however, in his review of the sites of sperm storage in bats, remarked upon the possibility that the spermatozoa seen in the testes of the canyon bat (Krutzsch, 1975) throughout the hibernation period were being stored. Krutzsch (1975), in his description of this unusual seminiferous population, suggested that continued nurturing of testicular spermatozoa may be advantageous to successful reproduction in the canyon bat. This bat undergoes repeated arousal and foraging periods in response to intervals of warm, sunny weather that are typical during winter in the southwestern deserts of North America. Some intermittent foraging activity may well result in the extrusion of epididymal spermatozoa. Continued male fecundity may rest on the availability of residual testicular spermatozoa, a factor that could be critical for successful reproduction in this species. The eastern pipistrelle, however, in the northeastern part of its range is a deep winter hibernator which rarely awakens to move about within the hibernaculum, let alone to embark on winter foraging (P. Krutzsch, unpublished observations). Even in Kentucky and Florida, where hibernation is at a higher temperature, these animals, although they waken and move, do so less frequently than do most bats (Barbour \& Davis, 1969). For this species, therefore, an assurance of continued fecundity during hibernation would not seem as important; nevertheless, it remains equally possible that the period of insemination extends into the winter in mild years and that the retention of testicular spermatozoa may be important for continued fecundity in this species also.

Eastern pipistrelles also differ from other hibernating vespertilionids (Miller, 1939; Pearson et al., 1952; Christian, 1956; Krutzsch, 1961, 1975; Racey, 1974; Racey \& Tam, 1974; Gustafson, 1976,1979 ) in that after the rise in accessory gland activity in the autumn (which may have been more marked had more animals been examined) the winter and summer cycles of these glands are not strongly differentiated. Fluctuations in the size and apparent fructose content of these organs exist, as in the common pipistrelle, P. pipistrellus (Racey \& Tam, 1974), but are not, in general, 
significant. Indeed, accessory gland regression (as measured by weight, fructose content and microscopic appearance) appeared to be limited only to a short period in mid-summer (July). It is possible that the accessory gland cycle is extended in the eastern pipistrelle as a function of the frequent persistence of hibernation into the early summer months, resulting in their almost continuous annual activity with only a short period (late June/July) of secretory quiescence. A similar explanation may hold for the unusual persistence of epididymal spermatozoa in this species. The resultant sperm storage period of some 9-10 months considerably exceeds that traditional for hibernating vespertilionids, with the exception of the lump-nosed bat, Corynorhinus rafinesquei ( = Plecotus townsendii), in which a similarly long period of sperm storage (epididymal) has been described (Pearson et al., 1952).

Testicular ascorbic acid is high in the rat (Setchell, 1978); it is apparently associated in some way with the maintenance of the seminiferous tubule epithelium and Leydig cells, and with spermatogenesis, since a deficiency results in degeneration of testicular tubules and interstitial cells (Leathem, 1961). However, the association between gonadotrophin-induced steroidogenesis and a fall in ascorbic acid that has been established for the adrenal gland and ovary in some mammalian species (e.g. Parlow, 1972) does not appear to hold for the testis, at least of the rat and dog (Noach \& van Rees, 1958; Llaurado \& Eik-Nes, 1961). In the present study, ascorbic acid levels in the testes followed the annual weight cycle of this organ, with an approximate 1 month lag between August and November, suggesting that a close correlation exists between testicular function and ascorbic acid content in the eastern pipistrelle. A similar situation was described for the leaf-nosed bat, Macrotus californicus (Krutzsch, 1976).

The testicular interstitial cells of the eastern pipistrelle display maximal hypertrophy during early spermatogenesis in summer (July/August) and show signs of involution before hibernation, as is typical of North American hibernating vespertilionids. Accessory sex gland response to the implied peak Leydig cell androgenesis in summer appears to be delayed by 1-2 months, with maximum dimensions and fructose levels being recorded in October. This apparent temporal dissociation of testicular endocrine activity and accessory target organ response that is typical of North American hibernating vespertilionids has been shown by Gustafson $(1976,1979)$ to be more apparent than real, as revealed by a close study of the activity of the accessory organ epithelia in the little brown bat. Although a real discrepancy between Leydig cell hypertrophy and recorded accessory organ function is suggested for the eastern pipistrelle by the delay in elevation of prostate and ampullary gland fructogenesis (a good criterion to evaluate accessory organ secretory activity (Burgos, 1974) which, in turn, is an indicator of androgen stimulation), further intensive examination of the activity of the Leydig cells and the response of the accessory organ epithelia are required before definitive statements can be made relative to the relationship between them, or to the cycle of activity of the accessory organs. However, the continuing presence of accessory gland fructose throughout hibernation suggests that androgens continue to be produced throughout this period.

No differences were noted in this study in the size and morphology of the baculum, as described by Hamilton (1949). The baculum differs markedly from that of the canyon bat, which is 4 times the length, more massive and greatly different in shape. In comparing the baculae of these two species, Hamilton (1949) remarks that "no other such marked interspecific variation has been noted" in the Chiroptera.

In conclusion, histological data suggest that the eastern pipistrelle behaves in a manner similar to other North American vespertilionid bats in displaying testicular gametic (and endocrine) functions in summer followed by a regression of the gonads before mating and hibernation; during hibernation, epididymal sperm stores and accessory gland hypertrophy are maintained. However, the eastern pipistrelle differs in its retention of some testicular spermatozoa and the fact that there are only slight differences seen in the summer versus winter activity of the accessory glands. It appears that hibernation is longer and the period of sexual quiescence is therefore shorter in the eastern pipistrelle than in other temperate vespertilionids. 
Barbour \& Davis (1969) question whether the canyon bat, Pipistrellus hesperus, and the eastern pipistrelle, $P$. subflavus, should be considered as belonging to the same genus. These authors referred to their strikingly different baculae (Hamilton, 1949; Krutzsch, 1975) and different chromosome numbers ( $P$. hesperus: 44; $P$. subflavus: 56; Baker \& Patten, 1967). Differences in the reproductive organ anatomy reported in the present paper would seem to be further evidence of the possible systematic distinction of these taxa.

We are especially indebted to Dr Mona Coetzee for her contributions to the fructose determinations and we also thank Mr Rob Murphy for excellent assistance with the illustrations and Mrs J. Brazier and Mrs B. Sheldon for patient secretarial assistance.

\section{References}

Baker, R.J. \& Patten, J.L. (1967) Karyotypes and karyotypic variation of North American vespertilionid bats. J. Mammal. 48, 270-286.

Barbour, R.W. \& Davis, W.H. (1969) Bats of America. University of Kentucky Press, Lexington.

Beasley, L.J. \& Zucker, I. (1984) Photoperiod influences the annual reproductive cycle of the male pallid bat (Antrozous pallidus). J. Reprod. Fert. 70, 567-573.

Beasley, L.J., Smale, L. \& Smith, E.R. (1984) Melatonin influences the reproductive physiology of male pallid bats. Biol. Reprod. 30, 300-305.

Burgos, M.H. (1974) Biochemical and functional properties related to sperm metabolism and fertility. In Male Accessory Organs: Structure and Function in Mammals, pp. 151-160. Ed. D. Brandes. Academic Press, New York.

Christian, J.J. (1956) The natural history of a summer aggregation of the big brown bat, Eptesicus fuscus fuscus. Am. Midl. Nat. 55, 66-95.

Gustafson, A.W. (1976) A study of the annual male reproductive cycle in a hibernating vespertilionid bat (Myotis lucifugus lucifugus) with emphasis on the structure and function of the interstitial cells of Leydig. Diss. Abstr. B 36, 4792- 4793.

Gustafson, A.W. (1979) Male reproductive patterns in hibernating bats. J. Reprod. Fert. 56, 317-331.

Gustafson, A.W. \& Shemesh, M. (1976) Changes in plasma testosterone levels during the annual reproductive cycle of the hibernating bat, Myotis lucifugus lucifugus, with a survey of plasma testosterone levels in adult male vertebrates. Biol. Reprod. 15, 9-24.

Guthrie, M.J. (1933) The reproductive cycles of some cave bats. J. Mammal. 14, 199-216.

Hamilton, W.J., Jr (1949) The bacula of some North American vespertilionid bats. J. Mammal. 30, 97-102.

Humason, G.L. (1967) Animal Tissue Techniques, 2nd edn. W. H. Freeman \& Co., San Francisco.

Jennings, W.L. (1958) The ecological distribution of bats in Florida. Ph.D. thesis, University of Florida, Gainesville.

Krutzsch, P.H. (1961) The reproductive cycle in the male vespertilionid bat Myotis velifer. Anat. Rec. 139, 309, Abstr.

Krutzsch, P.H. (1964) The reproductive cycle in the male bat of the species (Pipistrellus subflavus). Anat. Rec. 148, 303, Abstr.
Krutzsch, P.H. (1975) Reproduction of the canyon bat, Pipistrellus hesperus, in southwestern United States. Am. J. Anat. 143, 163-200.

Krutzsch, P.H. (1976) Reproductive biology of the male leaf-nosed bat, Macrotus waterhousii, in southwestern United States. Anat. Rec. 184, 61 1-636.

Leathem, J.H. (1961) Nutritional effects on endocrine secretions. In Sex and Internal Secretions, pp. 666-704. Ed. W. C. Young, Williams \& Wilkins Co., Baltimore.

Lindner, H.R. \& Mann, T. (1960) Relationship between the content of androgenic steroids in the testes and the secretory activity of the seminal vesicles in the bull. J. Endocr. 21, 341-360.

Llaurado, J.G. \& Eik-Nes, K.B. (1961) Immobility of ascorbic acid in the stimulated testis of rat and dog. Gen. comp. Endocr. 1, 154-160.

Miller, R.E. (1939) The reproductive cycle in the male bats of the species Myotis lucifugus lucifugus and Myotis gresescens. J. Morph. 64, 267-295.

Noach, E.L. \& van Rees, G.P. (1958) Ascorbic acid in the gonads of rats. Acta endocr., Copenh. 27, 502-508.

Parlow, A.F. (1972) Influence of differences in the persistence of luteinizing hormones in blood on their potency in the ovarian ascorbic acid depletion bioassay. Endocrinology 91, 1109-1112.

Pearson, O.P., Koford, M.R. \& Pearson, A.K. (1952) Reproduction of the lump-nosed bat (Corynorhinus rafinesquei) in California. J. Mammal. 33, 273-320.

Racey, P.A. (1974) The reproductive cycle in male noctule bats Nyctalus noctula. J. Reprod. Fert. 41, 391-402.

Racey, P.A. (1979) The prolonged storage and survival of spermatozoa in Chiroptera. J. Reprod. Fert. 56, 391-402.

Racey, P.A. \& Tam, W.H. (1974) Reproduction in male Pipistrellus pipistrellus (Mammalia: Chiroptera). J. Zool., Lond. 172, 101-122.

Roe, J.H. \& Kuether, C.A. (1943) The determination of ascorbic acid in whole blood and urine through the 2-4-dinitrophenylhydrazine derivative of dehydroascorbic acid. J. biol. Chem. 147, 399-407.

Setchell, B.P. (1978) Mammalian Testis. Paul Elek, London.

Wimsatt, W.A. (1944) Further studies on the survival of spermatozoa in the female reproductive tract of the bat. Anat. Rec. 88, 193-204. 
Wimsatt, W.A. (1945) Notes on breeding behaviour, pregnancy, and parturition in some vespertilionid bats in the eastern United States. J. Mammal. 26, 23-33.

Wimsatt, W.A. (1960) Some problems of reproduction in relation to hibernation in bats. Bull. Mus. comp. Zool. 124, 249-270.
Wimsatt, W.A. (1969) Some interrelations of reproduction and hibernation in mammals. Symp. Soc. exp. Biol. 23, 511-549.

Wimsatt, W.A. \& Trapido, H. (1952) Reproduction and the female reproductive cycle in the tropical American vampire bat Desmodus murinus. Am. J. Anat. 91, 415-446.

Received 11 March 1985 